\title{
Performance Evaluation of Phosphorous Removal by Coagulation using Natural Coagulants
}

\author{
S.Rajesh, P.Saravanan, S.Pauline, R.Premkumar
}

\begin{abstract}
Phosphorous is one of the major nutrients contributing the increased eutrophication of lakes and natural waters. The concentration of phosphorus in domestic sewage is generally adequate to support aerobic biological wastewater treatment. Coagulation and flocculation processes can also to remove phosphorous from industrial wastewater.In this experimental study, an attempt is made to feasibility of natural coagulants like Cassia Alata, Calotropis Procera, Hyacinth bean, Banana leaves, Carcia Papaya, Acacia mearnsii, Jatropha Curcas, Cactus and Tamarind seeds on the decrease of Phosphorous from Industrial wastewater. The batch coagulation test was done to optimum graph was plotted between the removal efficiency all the chose coagulated. From the optimum trails, that the rate of phosphorous removal is more for hyacinth bean with a level of 75, trailed by casuarinas leaves with $74 \%$ and Banana leaves with $73 \%$. Tamarind seed demonstrates the least Phosphorous expulsion from the wastewater with 56\%. From the optimum trails, the Hyacinth bean can be utilized as a successful coagulant for the expulsion of phosphorus from the wastewater. In the optimum trails coagulation studies were carried out to investigate the factor like optimum dosage, $\mathrm{pH}$, initial concentration of Phosphorous, Mixing time and the settling time which influences the removal of phosphorous by coagulation process. From the study, it might be inferred that the maximum percentage removal of phosphorous was acquired for the coagulant measurement of, $\mathrm{pH}$ of 8 , the initial phosphorous concentration of, mixing time of and settling time of 45 minutes. It might be presumed that the Phosphorous removal from the industrial wastewater of $95 \%$ was conceivable when we kept up the optimum condition by the coagulation procedure..
\end{abstract}

Keywords: Effective Coagulant, Industrial Waste Water, Natural Coagulant, Phosphorous Removal.

\section{INTRODUCTION}

A creating nation has numerous sorts of businesses and it releases countless various kinds of hurtful treated and untreated wastewater into the earth. Numerous kinds of ventures like the sustenance businesses, synthetic enterprises, items producing businesses, organic and agrarian ventures present in India. It is comprised of the high estimation of nitrogen, phosphorus, suspended solids, COD, BOD, smell,

Revised Manuscript Received on December 30, 2019.

* Correspondence Author

S.Rajesh*, Department of Civil Engineering, Kalasalingam Academy Research \& Higher Education, Krishnankoil,, India. Email: srajesh@klu.ac.in,rajeshkvm88@gmail.com

P.Saravanan, S.Pauline, Department of Civil Engineering, ACCET Karaikudi, India. Email:

R.Premkumar, Department of Civil Engineering, Kalasalingam Academy Research \& Higher Education, Krishnankoil,, India. Email: svanitha@klu.ac.in hues, natural, inorganic substance, living life forms, substantial metals, boss supplements are available in wastewater. These are daintily changed dependent on sorts of ventures wastewater and result of assembling in the businesses. [7]

Phosphorus present in local sewage was from nourishment deposits containing phosphorus and their breakdown items. The utilization of expanded amounts of manufactured cleansers adds generously to the phosphorus substance of sewage. Phosphorus is additionally a basic supplement for organic procedures. The grouping of phosphorus in household sewage is commonly sufficient to help high-impact organic wastewater treatment. In any case, it will involve concerned when the treated profluent is to be reused. The convergence of PO4 in crude sewage is commonly seen in the scope of 5 to $10 \mathrm{mg} / \mathrm{L}$. [6] [2], [12]

Phosphorous is one of the significant supplements adding to the expanded eutrophication of lakes and regular waters. Eutrophication of freshwater frameworks is one of the major ecological issues on our planet today. [3]

Coagulation and flocculation procedures can likewise be utilized to expel phosphorous from industrial wastewater. Coagulation is the way toward diminishing or killing the electric charge on suspended particles or zeta potential. Comparable electric charges on little particles in water cause the particles to normally repulse one another and hold the little colloidal particles separated and keep them in suspension. The most regularly utilized coagulant and flocculation help are alum, ferric chloride, and long-chain polymers. The utilization of alum as a coagulant in the treatment of water expands the aluminum fixation. A high convergence of aluminum is likewise of concern in light of its unfriendly impacts on wellbeing. Aluminum admission into the body has been connected with a few neuropathological sicknesses including percentile dementia and Alzheimer"es illness. There is additionally the issue of the response of alum with characteristic alkalinity present in water prompting the decrease of $\mathrm{pH}$ and low productivity in coagulation of virus waters. [2], [12] Ferric salts and manufactured polymers have additionally been utilized as coagulants yet with constrained achievement in light of similar weaknesses shown in the utilization of aluminum salts. Ooze created is voluminous and non-biodegradable after treatment and in this way presents transfer issues prompting an expansion at the expense of treatment. The expenses of these synthetic compounds have been expanding at a disturbing rate in creating nations. 
The powerlessness of neighborhood supplies to fulfill the interest because of finishing utilizes for imported synthetic compounds. This circumstance conjures another normal coagulant to handle the above-recorded issue. [5]

The primary favorable circumstances of utilizing regular plant-based coagulants as POU water treatment material are clear; they are savvy, far-fetched to deliver treated water with outrageous $\mathrm{pH}$ and very biodegradable. These favorable circumstances are particularly enlarged if the plant from which the coagulant is separated is indigenous to a country network. In the period of environmental change, exhaustion of earth's characteristic assets and across the board natural corruption, the use of these coagulants is a fundamental exertion in accordance with the worldwide feasible advancement activities. Utilization of plant-based coagulants for turbid water treatment goes back to more than a few centuries prior and so far, natural researchers have had the option to distinguish a few plant types for this reason. While it is justifiable that the coagulants are implied as basic residential POU innovation, there have additionally been various examinations centered on their use for the treatment of industrial wastewaters. [1]

The current study has to find the optimum natural coagulant in the removal of phosphorous and the optimum trails of coagulation study to investigate optimum dosage, $\mathrm{pH}$, initial concentration of Phosphorous, Mixing time and the settling time which influences the removal of phosphorous by coagulation process.

\section{MATERIALS AND MethodS}

\section{A. Collection of Industrial wastewater}

The example utilized for this was gathered from the Firework business close to the Sivakasi local Virudhunagar region, Tamil Nadu. The collected samples was stored in the refrigerator and it was used as stock solution.. The sample wastewater of required fixation was then arranged by diluting the required amount of wastewater in distilled water according to the necessity. The qualities of the industrial wastewater were examined in the research center according to the standard method. The characters of industrial waste were in table no. 1

Table-1: Characterization of Industrial Waste Water

\begin{tabular}{|l|l|l|}
\hline S.NO. & PARAMETER & VALUE(mg/l) \\
\hline 1. & pH & 7 \\
\hline 2. & COD & 80000 \\
\hline 3. & Total solids & 48000.95 \\
\hline 4. & Suspended solids & 39000.95 \\
\hline 5. & Dissolved solids & 9000.00 \\
\hline 6. & Total phosphorous & 4372.5 \\
\hline 7. & Chlorides & 78437.52 \\
\hline 8. & Sulphates & 43893.34 \\
\hline
\end{tabular}

\section{B. Preparation of Coagulants:}

Nine distinctive common coagulants like Cassia Alata, Calotropis Procera, Hyacinth bean, Banana leaves, Carcia Papaya, Acacia Mearnsii, Jatropha Curcas, Cactus and Tamarind seeds are chosen as a characteristic coagulant for this present examination. All the normal coagulants were gathered from the neighborhood showcase and adjacent local locations in Karaikudi, Tamil Nadu. At that point the gathered coagulants were either sun-dried or dried in the stove to evacuate the dampness substance present in it. At that point, the dried leaves were grounded in a processor. The ground materials were sieved in $0.425 \mathrm{~mm}$ sifter and the material went through it was utilized for further investigations.

Fine powder, the ground materials were sieved in $0.425 \mathrm{~mm}$ strainer and the material going through this sifter is utilized as a coagulant for these examinations.

\section{Estimation of Phosphorous}

The phosphorous level in the wastewater was distinguished utilizing UV Spectrophotometer.

\section{EXPERIMENTAL SETUP}

\section{A. Batch Coagulation tes}

The batch coagulation test was done to distinguish the powerful coagulant out of the chosen nine common coagulants for the expulsion of phosphorus from mechanical wastewater. This bunch coagulation test was completed according to the standard strategy. the example wastewater was taken in six $500 \mathrm{ml}$ containers and the first chosen coagulants were included the scope of 0,0.2.0.4,1,1.4,1.8,2.2 $\mathrm{g}$ to the measuring glasses. The measuring glass substance of $500 \mathrm{ml}$ was blended quickly for $120 \mathrm{sec}$ at $100 \mathrm{rpm}$ and this was trailed by $20 \mathrm{~min}$ of delicate blending at $35 \mathrm{rpm}$ to help in group development. The flocculated suspensions were permitted to remain without unsettling influence for $30 \mathrm{~min}$ to recreate settling. At that point, the settled measure of floc was estimated utilizing an estimating container. A similar method was rehashed for the staying chosen coagulant. The coagulant which delivers the most extreme measure of floc was chosen as a compelling coagulant. Further comparable group coagulation studies were done as disclosed above to streamline the parameter which influences the coagulation procedure.

\section{B. Recognizable proof of viable coagulant}

The batch coagulation test was done to decide the ideal coagulant measurements required for the expulsion of phosphorus in the wastewater. The Nine coagulants arranged as portrayed above were utilized for this group think about. To start with, the Jar Tests were completed for $500 \mathrm{ml}$ wastewater in six containers and various dosages of coagulant in the scope of $0,0.2,0.4,1,1.4,1.8,2.2$ grams were included the measuring utensils. Quickly following coagulant dosing, the measuring glass substance of $500 \mathrm{ml}$ was blended quickly for $120 \mathrm{sec}$ at $100 \mathrm{rpm}$ and this was trailed by $20 \mathrm{~min}$ of delicate blending at $35 \mathrm{rpm}$ to help in group development. The flocculated suspensions were permitted to remain without unsettling influence for $30 \mathrm{~min}$ to recreate settling. At that point, the settled measure of floc was estimated utilizing an estimating container. The outcomes were utilized to get the ideal coagulant measurement required for every coagulant. At that point, another group study was completed to decide the viable coagulant by including the ideal coagulant dose acquired through the past cluster ponder. The container test was executed according to the standard system. Subsequent to enabling the flocculated wastewater to settle the phosphorous stays in the supernatant fluid were broke down in a UV spectrophotometer. 


\section{RESUlts AND Discussions}

\section{A. Removal Efficiency of Various Coagulants}

A diagram was plotted between different coagulants and the rate expulsion of phosphorous as appeared in figure 1 .

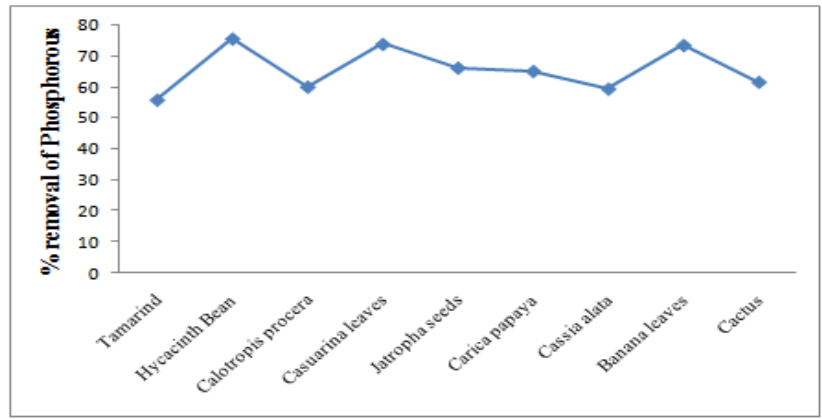

Fig.1: Removal Efficiency of Phosphorous for various Coagulant

From the diagram obviously, the rate expulsion of phosphorous is more for hyacinth bean with a level of 75 , trailed by casuarinas leaves with $74 \%$ and Banana leaves with $73 \%$. Tamarind seed demonstrates the least Phosphorous expulsion from the wastewater with $56 \%$. So from the chart, it very well may be inferred that Hyacinth bean can be utilized as a powerful coagulant for the expulsion of phosphorus from the wastewater.

\section{B. Effect of Coagulant Dosage:}

The chose coagulant was set up in a slurry structure by blending 10 grams of grounded and sieved normal coagulant in $100 \mathrm{ml}$ of refined water. The readied slurry was separated utilizing channel paper. The sifted slurry was then utilized as a coagulant. $500 \mathrm{ml}$ of the wastewater was taken and the readied slurry of $2 \mathrm{ml}$ to $24 \mathrm{ml}$ was added to the measuring utensils. The container test was then done according to the standard method. At that point, the supernatant fluid was dissected for the leftover phosphorus fixation. The rate evacuation of phosphorous was determined for various coagulant measurements and was plotted in the diagram as appeared in Figure 2. As portrayed from the chart, the rate expulsion of phosphorous increments with the coagulant dose. After the coagulant measurements of $20 \mathrm{ml}$, the rate evacuation of phosphorous declines. This might be because of the deflocculating of the settled floc.

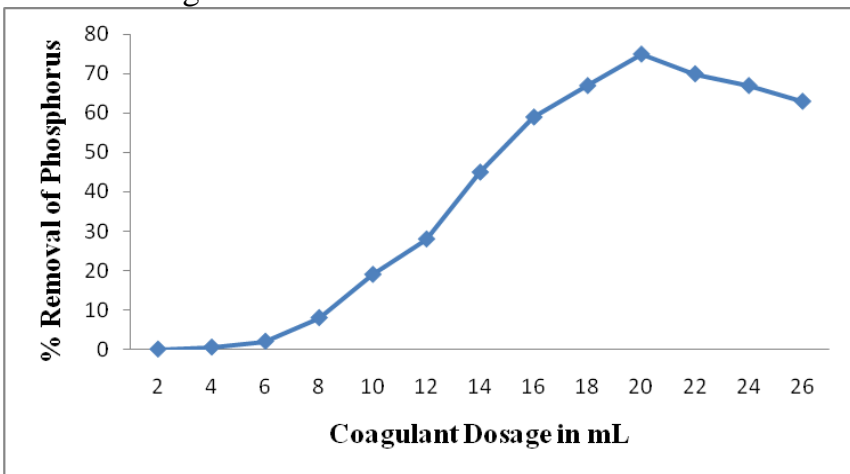

Fig.2: Phosphorus removal in percentage for different Dosage of Liquid Hyacinth Bean Natural Coagulant.

\section{Effect of $\mathrm{pH}$}

This optimization study was done by changing the $\mathrm{pH}$ estimation of the wastewater test as 4,5,6,7,8,9,10 with the assistance of $\mathrm{pH}-$ Meter. At that point the Jar test was done with the ideal coagulant measurement as decided in the past bunch ponder. The wastewater was then exposed to 2 minutes of fast blending and 20 minutes of moderate blending. At that point the wastewater was permitted to make due with 30 minutes. The measure of Phosphorous staying in the supernatant fluid was estimated and was plotted to think about the impact of $\mathrm{pH}$ on the expulsion of Phosphorous from industrial wastewater as appeared in Figure 3.

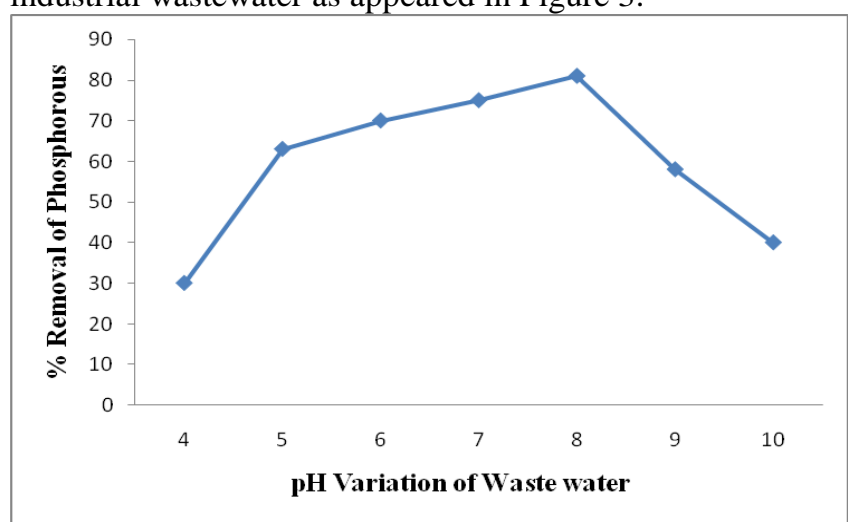

Fig.3: Phosphorus removal in percentage for Different pH of Waste Water with 20ml Dosage of Hyacinth Bean Natural Coagulant.

From the chart plotted above, plainly the rate expulsion of phosphorous increments as $\mathrm{pH}$ increments and it demonstrates the greatest evacuation rate when the $\mathrm{pH}$ was 8 . From that point onward, the evacuation rate begins diminishing

\section{Effect of Mixing Time:}

This optimization study was completed by changing the Mixing time of the wastewater test as $10,15,20,25,30,35,40$ minutes. At that point, the Jar test was completed with the ideal coagulant measurements as decided in the past clump think about. The $\mathrm{pH}$ of the wastewater was changed in accordance with 8 preceding the container test was completed. The wastewater was then exposed to 2 minutes of quick blending and 20 minutes of moderate blending. At that point, the wastewater was permitted to agree to 30 minutes.

The measure of floc settled was estimated and was plotted to examine the impact of Mixing Time on the expulsion of Phosphorous from industrial wastewater as appeared in Figure 4.

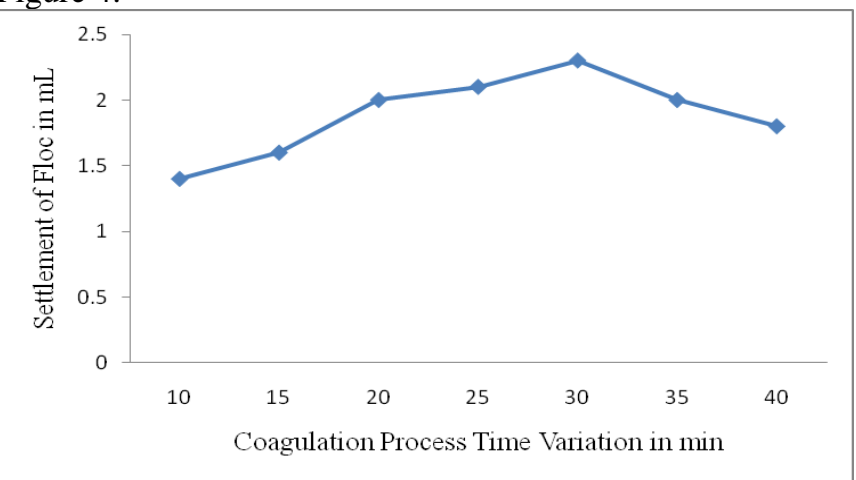

Fig.4: Phosphorus removal in percentage for different mixing time with $20 \mathrm{ml}$ Dosage of Coagulant and with pH of 8. 


\section{Performance Evaluation of Phosphorous Removal by Coagulation using Natural Coagulants}

From the chart plotted over, the settlement of floc increments with the blending time and achieves the most extreme estimation of $2.25 \mathrm{ml}$ with the blending time of 30 minutes. Following 30 minutes of blending time, the settlement of floc diminishes with an expansion in blending time.

\section{E. Effect of Settling Time}

This Optimization study was completed by fluctuating the settling time of the wastewater test from 10-55 minutes in the interim of 5 minutes. At that point, the Jar test was completed with the ideal coagulant measurements of $20 \mathrm{ml}$ as decided in the past bunch ponder. The $\mathrm{pH}$ of the wastewater was changed in accordance with 8 preceding the container test was completed. The wastewater was then exposed to 2 minutes of fast blending and 28 minutes of moderate blending as advanced in the past examination. At that point, the wastewater was permitted to settle from 10 to 55 minutes.

The measure of floc settled was estimated and was plotted to examine the impact of settling Time on the expulsion of Phosphorous from industrial wastewater as appeared in Figure 5.

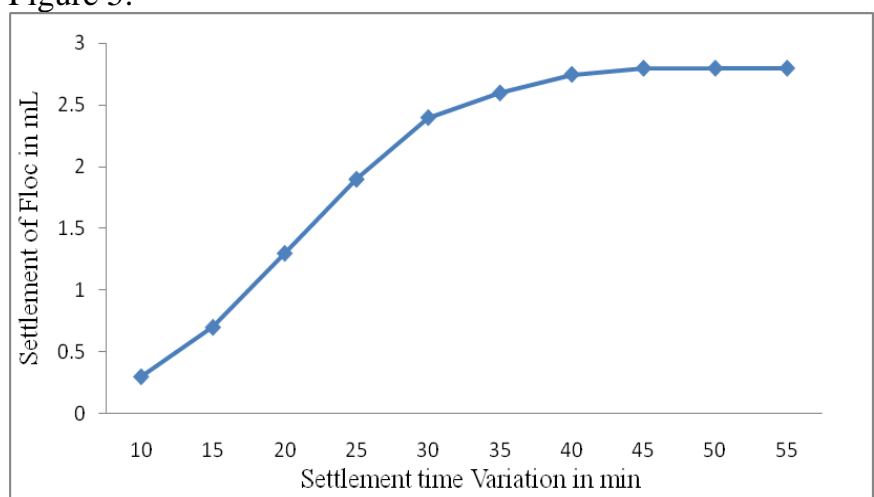

Fig.5: Phosphorus removal in percentage for different settling time with $20 \mathrm{ml}$ Dosage of Coagulant, $\mathrm{pH}$ of 8 ,mixing time of 30 minutes.

The volume of floc increments as the settling time increments and it achieves the most extreme worth when the settling time allowed was 45 minutes as portrayed in the chart appeared above fig 5 .

\section{Conclusion}

The investigation was done to assess the performance of natural coagulants in the phosphorus removal from industrial wastewater. Batch coagulation test was done to distinguish the successful coagulant (Hyacinth bean) and further batch studies were directed to think about the impact of the parameters like optimum coagulant measurement, $\mathrm{pH}$, mixing time-end settling time which influences the presentation effectiveness of the coagulation procedure. From the coagulation test, hyacinth bean demonstrated to be more powerful than the other chose coagulants (fig.1). From the optimization studies completed with hyacinth bean, it might be presumed that $95 \%$ (from fig 2,3,4,5) of phosphorous removal is conceivable if the optimum parameters were kept up appropriately as anticipated in this study.

\section{REFERENCES}

1. Abdelaal A.L. (Feb2004) "Using A Natural Coagulant Treating Wastewater"- Journal Of International Water Technology Conference.

2. Erik R. Coats, David L. Watkin, Cynthia K. Brinkman, Frank J. Loge,(May2011) "Effect Of Anaerobic HRT On Biological
Phosphorus Removal And The Enrichment Of Phosphorus Accumulating Organisms"-Journal Of Water Environment Research.

3. Leader, J.W, Reddyk.R. And Wilkie A.C, (Feb2002) "Optimization Of Low-Cost Phosphorus Removal From Wastewater Using Co-Treatments With Constructed Wetlands"- Journal Of Florida Water Science\& Technology.

4. Magnus Christensson And Jes La Cour Jansen, Kristina Göransson And Helene Möncke, (April2000) “ Influence Of Calcium And Ph On The Enhanced Biological Phosphorus Removal In A Sequencing Batch Reactor System Treating Dairy Wastewater" - Science Thesis Of Lund Institute Of Technology / Lund University, Dept Of Water And Environmental Engineering

5. Plaza.E, Levlin.E, Hultman.B, (Jul2008) "Phosphorus Removal From Wastewater" - Journal Of Swedan Water Science\& Technology.

6. Renuka A. Binayke, Prof. M.V.Jadhav (Ju12013) "Application Of Natural Coagulants In Water Purification"- International Journal Of Automation And Control Engineering.

7. Shilpa.B.S, Akanksha, Kavita, Girish.P, (June 2012) "Evaluation Of Cactus And Hyacinth Bean Peels As Natural Coagulants"International Journal Of Chemical And Environmental Engineering.

8. S.Rajesh and Premkumar R , and Jeyadevi Neethipathi 2019, Relative Effectiveness of Methane (Biogas) Production from Dry Grass Soaked with Vegetable Waste, Poultry Waste and Cow Dung, Oriental Journa of Chemistry, Volume 35,Issue 2,April 2019,PP 732-737.

9. S.Sowmiya Lakshmi,S.Rajesh and Premkumar R ,2018, Removal of Organic Pollutants From Textile Dye Wastewater By Advanced Oxidation Process, International Journal of Civil Engineering \& Technology, (IJCIET),Volume 9,Issue 4,April 2018,:PP 452 - 461.

10. Sundaram haridoss, 2017.Study on air quality management in adyar river basin: A review, Journal of Industrial Pollution Control 33(1):PP 730-740.

11. Tom Harner, Ky Sua, Susie Genualdia, and Jessica Karpowicza 2013. Short communication Calibration and application of PUF disk passive air samplers for tracking polycyclic aromatic compounds (PACs) Atmospheric Environment International Journal, Science direct Vol.75:PP 123-128.

12. WANG Ya, PAN Mian, YAN Min, PENG Yong-Zhen, WANG Shu-Ying,(Dec2006) "Characteristics Of Anoxic Phosphors Removal In Sequence Batch Reactor”-Journal Of Environmental Sciences.

\section{AUTHORS PROFILE}

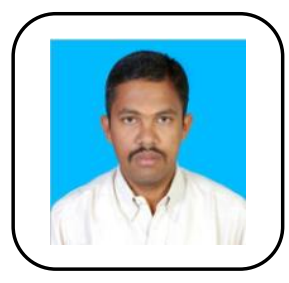

Er.S.Rajesh Completed B.E(Civil) degree from GCE, Tirunelveli in 2009 and M.E(Environmental) degree from ACCET,Karakudi in 2013. He is working as Ass professor in KARE, Krishnankoil and Research scholar in KARE.His research area is Envionmental Engineerring..He is having 7 years Academic Experience and 10 years Industry consultancy Experience. $\mathrm{He}$ is Chartered Engineer \& Valuer in India. He is Professional member of the IOV, IEI and PE. He has published more than 10 SCOPUS indexed Journal and Conference in and around India.

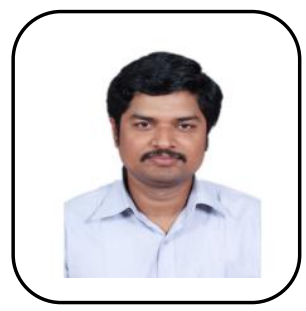

Er. R.Premkumar had completed B.E degree in Civil Engineering and M.E degree in Structural Engineering from Anna University, Chennai, Tamil Nadu in 2008 and 2012 respectively. $\mathrm{He}$ is currently working as Assistant Professor in the department of Civil Engineering at Kalasalingam Academy of Research and Education. He has 2 year of industrial experience and 7 years experience in academics and consultancy. His current research interests are Geopolymer Concrete and Earthquake resistance structures. 